\title{
Editorial
}

\section{Implicaciones del ingreso de Colombia a la OCDE}

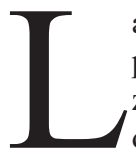

a Organización para la Cooperación y el Desarrollo Económico (OCDE) surgió en la posguerra por iniciativa de los líderes europeos, quienes consideraron que para alcanzar una paz duradera, lo mejor era "fomentar la cooperación y la recuperación, en vez de castigar a los vencidos".

La Organización para la Cooperación Económica Europea (OCEE), antecesora de la OCDE, fue creada en 1948 con el fin de administrar el Plan Marshall, cuyos recursos fueron aportados por Estados Unidos con el propósito de reconstruir el Viejo Continente, devastado por el conflicto bélico. Como dicha organización fue un éxito, sus líderes optaron por hacerla extensiva al ámbito mundial; es así como Canadá y Estados Unidos se integraron a la OCEE, al transformarse esta en la OCDE el 14 de diciembre de 1960.

La OCDE, tal y como se conoce actualmente, surgió el 30 de septiembre de 1961, cuando el acuerdo se oficializó. Después, nuevos países se sumaron a la Organización, como Japón en 1964, y posteriormente se unieron otros, no solo desarrollados, sino también subdesarrollados. Hoy en día, dicha institución está compuesta por 37 países, incluido Colombia, el cual fue admitido en este grupo de países después de siete años de negociaciones y de cumplir con una serie de requisitos.

La OCDE tiene como función principal impulsar políticas públicas que eleven el bienestar tanto económico como social de la población, y les permite a los diferentes gobiernos participar en deliberaciones periódicas en las que se comparten experiencias y se trata de resolver las dificultades generales de los diversos países por medio del trabajo participativo.

Para que un país pueda llegar a ser miembro de la OCDE, debe, no solamente, recibir una invitación directa, sino también contar con la aceptación de todos los demás integrantes, ya que la admisión no se da por mayoría, sino mediante consenso.

Una vez que el país es aceptado, asume una serie de obligaciones en áreas sociales, económicas y ambientales; además, el Congreso de la República debe legislar sobre el particular.

Debido a que la OCDE funciona como un club, cada país debe aportar una cuota anual que está determinada por dos variables: una parte que es fija, que es igual para todos sus miembros, y otra que es proporcional al tamaño de su economía. Teniendo en cuenta el aporte que hacen países como Chile y otros con economías muy parecidas a la austral, el Centro de Estudios Latinoamericanos (CELA) estima que Colombia deberá contribuir, anualmente, con un monto aproximado a los cinco millones de dólares. 
Empero, el compromiso mayor de Colombia tiene que ver con la ejecución de las recomendaciones de los 23 comités temáticos, que abarcan asuntos ambientales, comerciales, tributarios, educativos, laborales, entre otros. Según el informe del CELA, Colombia "tendrá que invertir cerca de 20 billones de pesos anuales por los próximos 15 años, o sea una cifra que podría aproximarse a 300 billones de pesos o hasta tres veces superior al monto estimado para la implementación de los acuerdos de paz con las FARC".

En términos generales, pertenecer "al club de los nuevos ricos" o "de las buenas prácticas", como algunos llaman a la OCDE, es un privilegio que resulta bastante costoso. Por eso es interesante preguntarse cuál o cuáles son los beneficios para Colombia. Sobre el particular, las opiniones están divididas. Para algunos analistas, como Miguel Gómez Martínez, Alejandro Valencia, Diego Guevara, entre otros, el país no tiene ni los recursos ni la disposición para llevar a cabo las orientaciones ni las buenas prácticas que exige la institución; y para otros, como Salomón Kalmanovitz, Juan Ricardo Ortega y en general para los gremios de la producción, el país obtendrá una serie de beneficios que, sin duda, afectarán positivamente a la mayoría de la población.

Es bueno aclarar que las disposiciones de la OCDE no son vinculantes; la Organización aconseja una serie de medidas y prácticas que en otros países han dado buenos resultados y que el país en cuestión está en libertad de ejecutarlas o no. Sin embargo, Colombia, en la fase de negociación, implantó una serie de reformas para mostrarle a la OCDE que el país puede emprender reformas unilaterales y, de esta forma, ajustarse a sus requerimientos; no obstante, muchos son los temas que el país debe adecuar a los parámetros y exigencias de esta institución.

El equipo económico del Gobierno y el mismo presidente Santos han insistido en que la pertenencia a la OCDE genera grandes beneficios al país en áreas como la inversión extranjera, la protección a la actividad sindical, la educación, la salud, el medio ambiente, entre otras. Pero, no hay que olvidar que en la segunda mitad del año habrá cambio de Gobierno y que es posible que la administración entrante no tenga las mismas prioridades y los mismos objetivos que la de Santos. En todo caso, no se puede pasar por alto que Colombia necesita cambios profundos en diferentes áreas que, verdaderamente, mejorarán las condiciones de vida de la población.

Es preciso señalar que los problemas más preocupantes tienen que ver con la desigualdad y la informalidad laboral. Con relación a la primera, Colombia es el tercer país más desigual del mundo, con un coeficiente de Gini en el sector urbano de 0.51, y en el sector rural de 0.90; es de esperar que las reformas en educación, salud e infraestructura, así como en el sistema financiero y en el campo, entre las más importantes, contribuyan a reducirla.

Por otro lado, la informalidad laboral presenta cifras alarmantes, siendo más acentuada en el sector rural; pues mientras que en el sector urbano (23 áreas metropolitanas) en el 2017 fue del $50.8 \%$, en el sector rural fue del $82 \%$. Bien vale, entonces, preguntarnos: ¿habrá voluntad política de la nueva administración para resolver una situación como la descrita? o ¿nos quedamos con el diagnóstico y no con las soluciones?

Luis Eudoro Vallejo Zamudio Director de la Revista Apuntes del Cenes 